\title{
Approach and avoidance in moral psychology: Evidence for three distinct motivational levels
}

\author{
James F. M. Cornwella \& E. Tory Higgins ${ }^{\mathrm{a}}$ \\ aColumbia University, Department of Psychology, 406 Schermerhorn Hall, 1190 \\ Amsterdam Ave. MC 5501, New York, NY 10027
}

Email addresses:

Cornwell: jfc2134@columbia.edu; Higgins: tory@psych.columbia.edu

Corresponding author: James Cornwell

Phone: (212) 854-8464/(716) 868-9830; Fax: (212) 854-3609

Acknowledgements: This research was supported by a graduate research fellowship awarded by the National Science Foundation to James Cornwell. 
During the past two decades, the science of motivation has made major advances by going beyond just the traditional division of motivation into approaching pleasure and avoiding pain. Recently, motivation has been applied to the study of human morality, distinguishing between prescriptive (approach) morality on the one hand, and proscriptive (avoidance) morality on the other, representing a significant advance in the field. There has approach and avoidance within morality, as if one could proceed with a "one size fits all" perspective. In this paper, we argue for the unique importance of each of three different 11 moral motive distinctions, and provide empirical evidence to support their distinctiveness. 12 The usefulness of making these distinctions for the case of moral and ethical motivation is 13 discussed.

Keywords: motivation, approach, avoidance, morality, values 


\section{Introduction}

The study of ethics in the context of psychological science has undergone considerable advances over the past two decades, receiving renewed attention from researchers working at myriad levels of analysis. This research has ranged from the processes and neurological correlates of moral judgment (e.g. Greene \& Haidt, 2002) to the development of pro- and anti-social tendencies in infants (e.g. Hamlin, Wynn, \& Bloom, 2007).

During this same period, research on the science of motivation has similarly advanced, with a variety of different theories of motivation being put forward that broaden and deepen the understanding of motivation beyond the useful, but ultimately too simple, hedonic model of approaching pleasure and avoiding pain. These theories range from deepening the model of approach/avoidance to include behavioral control theories of activation and inhibition (Carver \& White, 1994; Carver \& Scheier, 2001) to regulatory focus theories of strategic inclinations (Higgins, 1997; 1998). Other research has expanded on these motives in research on achievement (Elliot, 1999) and different modes of goalpursuit (Kruglanski et al, 2000).

In the last decade, these two lines of research intersected. First, the principles of regulatory focus and regulatory fit were examined in the context of moral value (Camacho, Higgins, \& Luger, 2003). Later, the overarching principles of approach and avoidance were fleshed out in more detail with respect to moral rules (Janoff-Bulman, Sheikh, \& Hepp, 2009). This represents an important advance both in the science of morality and the 22 science of motivation. 
However, in contrast to the increased complexity in motivation science, there has been some tendency to subsume all motives under those corresponding to approach and avoidance within morality, namely the prescriptive (approach) and proscriptive (avoidance) systems of moral motivation (cf. Janoff-Bulman \& Carnes, 2013). In developing the intersection of motivation science and moral psychology, these theories may be paying too little attention to important distinctions already established in the wider motivation

\section{Distinguishing Motivational Theories}

The first task is to theoretically distinguish each of the theories from a larger, simplified approach/avoidance construct. Consistent with developments in motivation science (see Scholer \& Higgins, 2008), we propose that each of the constructs under consideration in this manuscript occupies a distinct level of motivation. The "system" level of motivation refers to the tendency to approach desirable end-states and avoid undesirable end-states. The "strategic" level of motivation refers to the tendency to engage in this approach or avoidance in a strategic eager manner or a strategic vigilant manner based on how the goals are conceptualized (i.e., as either "ideals" or "oughts," respectively). 
1 Finally, the "tactical" level of motivation refers to the particular motivational demands of 2 the situation in which individuals find themselves, requiring either behavioral activation or 3 inhibition. Figure 1 illustrates how each level of motivation can be active when 4 determining a course of action with respect to morality. According to this proposal, each of 5 the distinct motives that we examine will be functionally independent of the others and 6 make independent contributions to moral phenomena because each occupies a unique $7 \quad$ level motivationally.

Since the prescriptive and proscriptive systems are, in essence, a description of approach and avoidance orientations at the system level in morality (Janoff-Bulman, Sheikh, \& Hepp, 2009), below we will describe regulatory focus theory and control theory, their distinctions from this system level of approach/avoidance, and how each has been examined in the context of moral psychology. In the process, we hope to establish that examining only approach/avoidance at the system level does not provide a full account of moral motivation.

Regulatory Focus Theory

According to regulatory focus theory, there are two distinct strategic systems of goal pursuit. The promotion focus is associated with the pursuit of ideals and growth goals, concerned with the advancement from the status quo to a better state. The prevention focus is associated with the pursuit of oughts and security goals, concerned with the maintenance of the status quo against falling to a worse state (Higgins, 1997; 1998). Myriad lines of research have examined the importance of this distinction for both judgment and decision making (e.g., Scholer et al, 2010; Zou, Scholer, Higgins, 2014) and behavior (e.g., Förster, Higgins, \& Idson, 1998; Freitas, Liberman, \& Higgins, 2002). 
As mentioned in this theory's earliest conceptualizations, it is important not to conflate promotion and prevention with, respectively, approach and avoidance at the system level. Theoretically speaking, both the promotion ideal and prevention ought systems are approach systems (Higgins, 1997; 1998; see Förster et al., 1998). Indeed, Förster et al. (1998) found a "goal looms larger" effect for both promotion and prevention where participants became increasingly motivated as they approached the final desired produce negative affect, indicating that both are desired end-states to be approached (Higgins, 1987; Shah, 2003).

With respect to morality, some research shows similar effects of promotion and prevention and approach and avoidance. For example, both promotion and approach are more concerned about failures of omission, whereas both prevention and avoidance are more concerned about failures of commission (Camacho et al., 2003; Janoff-Bulman, Sheikh, \& Hepp, 2009). And with respect to moral judgment, both the prevention system and proscriptive (avoidance) system of morality have been associated with binding moral foundations (Cornwell \& Higgins, 2013; Janoff-Bulman \& Carnes, 2013). However, rather than indicating that the constructs are the same, instead, we believe that this suggests that they have distinct reasons for this overlap-that each construct is accounting for different parts of the variance in moral judgment and value.

This position is supported by the ways in which approach/avoidance and promotion/prevention differ in the domain of morality. For example, if approach is concerned with bringing about positive end-states (rewards) and avoidance is concerned with avoiding negative end-states (punishments), and promotion and prevention just 
represent instantiations of this fundamental principle in the area of morality, then promotion-focused individuals should be more approving of rewards for good behavior and prevention-focused individuals should be more approving of punishments for bad behavior. Instead, research has shown that both promotion- and prevention-focused individuals approve of both punishments and rewards equally, only showing preferences for different kinds of strategic rewards and punishments (eager rewards and punishments for promotion; vigilant rewards and punishments for prevention; see Camacho, Higgins, \& Luger, 2003). Recently additional research (Wisneski, 2014) directly investigating the properties of the prescriptive/proscriptive distinction in light of regulatory focus theory found no link between experimental inductions of regulatory focus and the prescriptive/proscriptive "group” motives from Janoff-Bulman, Sheikh, \& Baldacci (2008), while at the same time it did provide further evidence for the importance of these distinct motives for understanding differences in political ideology.

Control Theory

The control theory of motivation is distinct from both system-level approach/avoidance and the strategic-level regulatory focus theory of motivation (see Scholer \& Higgins, 2008). Rather than operating at the strategic level like regulatory focus, the control theory operates at the tactical behavioral level, relating to tendencies to activate behavior or inhibit behavior in response to circumstances (Carver \& Scheier, 2001). These responses to the concrete situational characteristics eventually take on the form of motivational orientations, which correspond to the behavioral activation systems (BAS) and the behavioral inhibition system (BIS), respectively (Carver \& White, 1994). 
As with regulatory focus, these orientations are implicated in the approach of desired end-states and the avoidance of undesired end-states, but they are theoretically distinct from the orientations toward one or the other end-state (see Scholer \& Higgins, 2008). Sometimes the achievement of a desired end-state involves the activation of of a goal), the inhibition of behavior can be involved in the achievement of these desired end-states. Similarly, the avoidance of undesired end-states frequently requires the inhibition of behavior, but avoiding negative outcomes can also require the activation of behavior (e.g., running away from danger).

In terms of distinct associations of morality with BIS and BAS, research has shown that those with a stronger BAS compared to those with a stronger BIS are more likely to deem it ethical to kill one individual to save more in scenarios like the classic "trolley" dilemma (Van den Bos, Müller, \& Damen, 2011). Research has also shown moral disgust to be associated with behavioral inhibition (Olatunji et al., 2008). These results seem consistent with a general approach/avoidance model of moral regulation, but it remains to be examined whether there are also unique associations between BIS and BAS and moral constructs independent of those captured by the prescriptive/proscriptive model. Finally, it should also be noted that regulatory focus and BIS and BAS are distinct from one another as well. Research has shown that the scales associated with the measurement of each of the motivational orientations tap into unique constructs (Summerville \& Roese, 2008). In addition, recent research in neuroscience has found that they are associated with different patterns of brain activation (Strauman \& Wilson, 2010; 
1 Strauman et al., 2013). Since the distinction between these two theories has been more widely studied and established, it will not be a major focus of the research in this paper.

\section{The Present Research}

In sum, the weight of the evidence from motivation science research argues against viewing these theories in terms of a "one size fits all" approach/avoidance principle. In addition, a conceptual alternative perspective exists that distinguishes among these theories in terms of different levels of motivation (Scholer \& Higgins, 2008). Nonetheless, we recognize that it may still be possible to maintain that the conceptual distinctions are unimportant in the field in which they have most recently been conflated: moral psychology. Perhaps, despite the evidence discussed above, the moral approach (prescriptive) system inherently has the properties both of behavioral activation and of the growth concerns of the promotion focus, and the moral avoidance (proscriptive) system inherently has the properties both of behavioral inhibition and of the security concerns of the prevention focus. In order to test this possibility, we will examine the three theories of motivation simultaneously. The first is the system-level approach/avoidance construct in moral psychology presented in Janoff-Bulman, Sheikh, and Baldacci (2008). The Moral Motives Scale developed in this research offers a useful empirical tool with which to examine the theory's relationship to other constructs in motivation science. The second and third distinctions, BIS/BAS and regulatory focus, have been theoretically implicated in the work of Janoff-Bulman, Sheikh, and Hepp (2009).

A secondary aim of our research, particularly Studies 2 and 3, is to extend past research on the three different kinds of motivational distinctions by examining them in the context of a new measure of the moral emotions of guilt and shame and comprehensive 
examination of personal values, which can have implications for moral attitudes (Schwartz, Caprara, \& Vecchione, 2010) and moral behavior (Schwartz \& Howard, 1984). In addition to demonstrating that each of the distinctions makes an independent contribution to moral

5 relations between these constructs and important moral psychology domains. This will not

only provide a more complete understanding of the unique contributions that the

prescriptive/proscriptive distinction, the promotion/prevention distinction, and the

BIS/BAS distinction have to offer to moral psychology, but it will also show how examining

approach/avoidance at multiple levels of analysis (system level; strategic level; tactical level) can paint a fuller picture of moral motivation.

\section{Study 1}

The purpose of our first study was to show empirically that the various motivational constructs are distinct from one another. We examined the three theories (approach/avoidance, BAS/BIS, and promotion/prevention) using their respective questionnaires (the Moral Motives Scale, the BIS/BAS scale, and the Regulatory Focus Questionnaire). If the three theories are merely aspects of the same larger construct, then the "approach" constructs should be associated and the "avoidance" constructs should be associated. Furthermore, if these distinctions are reflective of larger underlying constructs (i.e., approach and avoidance), then a confirmatory factor analysis should show that models that collapse across the "approach" and "avoidance" constructs have comparable goodness of fit to models that specify the constructs as they are found in their respective separate theories.

\section{Method}




\section{Participants}

Four hundred six participants were recruited from Amazon's Mechanical Turk for the sum of $\$ 1.00$. The sample consisted of 226 females and 180 males. We did not collect

Every participant filled out the three scales associated with the three motivational constructs of interest. The scales were the Moral Motive Scale (MMS; Janoff-Bulman, Sheikh, \& Baldacci, 2008), the Regulatory Focus Questionnaire (RFQ; Higgins et al, 2001), and the BAS/BIS questionnaire (Carver \& White, 1994) presented in random order. The MMS consists of 20 items on a scale from 1 ("strongly disagree") to 7 ("strongly agree") assessing agreement with particular kinds of moral principles. Each item is associated with one of four subscales: self-reliance (approach-self; e.g., "I'm willing to put the necessary time and effort into providing for my own well-being and success."), self-restraint (avoidance-self; e.g., "It's particularly important for me to demonstrate self-control in the face of temptation."), social justice (approach-other; e.g., "If we look after ourselves, we still need to look after others in society."), and social order (avoidance-other; e.g., "Giving people the freedom to choose the way they live threatens the societal bonds that hold us together."). 
The RFQ consists of 11 items rated on scale from 1 ("never or seldom") to 5 ("very

often") assessing the degree to which participants feel they are effective in achieving promotion goals (e.g., "How often have you accomplished things that have gotten you "psyched" to work harder?") and effective in achieving prevention goals (e.g., "How often with one of two subscales: promotion focus and prevention focus. Finally, the BIS/BAS questionnaire consists of 24 items (including 4 irrelevant non-scored items) rated on scales from 1 ("very true for me") to 4 ("very false for me")-scores were reversed during collection for ease of analysis. Each item (with the exception of four distractor items) is associated with one of four subscales: BAS fun seeking (e.g., "I'm always willing to try something new if I think it will be fun."), BAS reward (e.g., "When I'm doing well at something, I love to keep at it."), BAS drive (e.g., "When I want something I usually go allout to get it."), and BIS (e.g., "Criticism or scolding hurts me quite a bit."). In the end, each participant received a score for self-reliance, self-restraint, social justice, social order, BAS drive, BAS fun-seeking, BAS reward, BIS, promotion focus, and prevention focus. Results

Each pair of motivational constructs was entered into a partial correlation controlling for sex differences and relations with the other constructs. This approach allowed us to examine the relations among the subscales that are unique over and above the relations with other subscales. The full set of partial correlations can be found in Table 1. However, because some of the correlations found in Study 1 did not replicate across samples in Studies 2 and 3, we will detail the relations among the scales in a combined analysis following the final study. 
The second aim of Study 1 was to determine whether the multiple-construct approach produces the best fit for the different items, or if they can be just as well represented using a general "approach" and "avoidance" construct. Therefore, we performed four confirmatory factor analyses. In the first two analyses, we looked at the "approach" scales (i.e., the three BAS subscales, promotion, self-reliance, and social justice). The first CFA included each scale as a latent variable with its scale items as its indicators. The second CFA used the same items, but rather than organizing them according to their associated constructs, we listed them adjacently, subdividing them into 6 parcels (this was to ensure that both CFAs had the same number of latent variables). This same technique was used for the latter two CFAs, except that the items used were those associated with the "avoidance" constructs (i.e. BIS, prevention, self-restraint, and social order).

The two models organized around the constructs as independent showed adequate to good fit. The "approach" model had an RMSEA of 0.059 and a CFI of 0.90 , both of which represent the cutoff scores for acceptable model fit. The "avoidance" model showed better fit, with an RMSEA of 0.058 and a CFI of 0.93 . However, both of these models were far superior to the models that assumed a larger "approach" or "avoidance" underlying construct. The "approach" model of this type had an RMSEA of 0.118 and a CFI of 0.59 , and the "avoidance" model had an RMSEA of 0.14 and a CFI of 0.53. All of these statistics reflect a poorly fitting model for the data. It should be noted that in every one of the CFAs, the chisquare statistic was significant, but this is often the case with large samples even when the model fits adequately.

Discussion 
The results do not support the notion that these subscales are interchangeable with

respect to a larger approach or avoidance construct. A CFA making use of the "approach" and "avoidance" items contained in the three questionnaires showed substantially better fit when adapted to the existing constructs, rather than generalized across the various constructs along a broader "approach" or "avoidance" continuum. What these results highlight is the importance of treating these constructs as functionally independent.

Our results further suggest that even if the three questionnaires were to have some similar effects in certain cases, the independence of the motivational dimensions underlying these questionnaires suggests that they would have done so for different reasons. With this in mind, we now turn to an important follow-up question: even if approach/avoidance, regulatory focus, and BIS/BAS represent distinct motivational constructs, do they have independent, distinct relations to moral phenomena? It is certainly possible that, though the constructs are distinct, those constructs explicitly related to morality (i.e., the prescriptive/proscriptive distinction) could explain so much of the variance in morality research that it makes little sense to examine relations to regulatory focus and BIS/BAS in addition to approach/avoidance. This is the question we sought to address in Studies 2 and 3.

\section{Study 2}

As stated above, even though approach/avoidance moral motives, regulatory focus, and BIS/BAS are all empirically distinct motivational constructs, it remains to be seen whether the latter two theories, as broader theories of motivation rather than of morality per se, can make predictions about moral phenomena independent of the approach/avoidance moral motives. If the approach/avoidance moral motives represent 
the expression of the regulatory focus and BIS/BAS distinctions within the domain of morality, then, when controlling for those motives, promotion, prevention, BAS, and BIS should not significantly explain any additional variance of moral phenomena. To test whether this is the case, we chose to study the three motivational constructs in a context to which they can all be theoretically related: moral emotions.

In this study, following the recent work of Cohen, Wolf, Panter, and Insko (2011), we examined guilt and shame from two aspects. According to Cohen and colleagues' (2011) research, guilt and shame each has an experiential component and a behavioral component. The former corresponds to the degree to which an individual is prone to experiencing a particular moral emotion following a transgression, and the latter describes the proneness towards the behavioral consequence of that feeling. With respect to guilt, the emotional experience (negative behavior evaluation or NBE) and behavior (repair) follow private transgressions. With respect to shame, the emotional experience (negative self evaluation or NSE) and behavior (withdrawal) follow public transgressions. Each of these tendencies can be measured using the Guilt and Shame Proneness Scale (GASP; Cohen et al, 2011), which contains four subscales corresponding to each of these characteristics. ${ }^{1}$

These emotions have important theoretical links to each of the motivational constructs examined in this paper. With respect to MMS approach/avoidance, research has shown that guilt is motivationally related to the approach system, and shame is motivationally related to the avoidance system (Sheikh \& Janoff-Bulman, 2010). This same line of research showed similar effects for BAS and BIS, though this study used a different

\footnotetext{
${ }^{1}$ In their original piece validating the GASP, Cohen et al. (2011) examined the four subscales' relations to promotion and prevention using the questionnaire developed by Lockwood, Jordan, \& Kunda (2002). Our approach involves different scales with favorable psychometric properties (see Summerville \& Roese, 2008), therefore our results should be seen as complementary to those reported in the original GASP scale paper.
} 
measure of guilt and shame (the Test of Self-Conscious Affect-3R; see Tangney et al, 2000) that does not differentiate the experiential and behavioral elements associated with these two emotions the way that the GASP does (Cohen et al, 2011).

The promotion focus and prevention focus may have theoretical connections to these emotions indirectly through work on self-discrepancy theory. Self-discrepancy theory (Higgins, 1987) proposed that guilt emotions would be more associated with discrepancies between the actual self and the prevention-related ought self (specifically, your own beliefs about your duties and obligations), whereas discrepancies between the actual self and the promotion-related ideal self (specifically, what others hope and wish you will be) would be more associated with shame than guilt emotions.

However, it should be emphasized that these predictions involve standpoint (own $v s$. other, respectively) and not just focus, and the GASP measure does not include distinctions based on standpoint. Thus, it is difficult to make precise predictions for this measure based on self-discrepancy theory, or whether there will be reliable associations at all. And, as noted earlier, both oughts and ideals are desired end-states that people are motivated to approach. Thus, they might both function like approach systems, relating to guilt.

With this past research in mind, the following study investigated whether the promotion/prevention and BIS/BAS motivational constructs failed to explain significant portions of the variance beyond the MMS approach/avoidance moral motives or if these three constructs have independent relations to moral emotions.

\section{Method}

Participants 
One hundred twenty participants, recruited from the Columbia Business School's

Behavioral Research Lab which is open to the larger Columbia community, took part in the study for the chance to enter a raffle to win $\$ 70.00$. Participants consisted of 72 females,

45 males, and 3 unspecified individuals. Age data was not collected, but approximately $90 \%$ of the sample $(\mathrm{N}=105)$ indicated having at least some college education. There were no sex differences for any of the variables described below.

Procedure

The study procedure was identical to that in Study 1 except in one respect. Participants filled out the Moral Motives Scale (MMS; Janoff-Bulman,Sheikh, \& Baldacci, 2008), the Regulatory Focus Questionnaire (RFQ; Higgins et al, 2001), and the BAS/BIS questionnaire (Carver \& White, 1994) in random order. Following these scales, participants filled out the Guilt and Shame Proneness Scale (GASP; Cohen et al., 2011). The GASP consists of 16 scenarios involving some form of moral transgression from the participants' point of view, probing the perceived likelihood of experiencing one of these moral emotions (guilt NBE or shame NSE) or engaging in one of their associated behavioral responses (guilt repair or shame withdrawal). Each item was rated on a scale from 1 ("Very Unlikely") to 7 ("Very Likely") and provided each participant with four moral emotion proneness subscales: guilt negative behavior evaluation or NBE, shame negative self evaluation or NSE, guilt repair, and shame withdraw.

Results

As in Study 1, we organized the partial correlations (independent associations of each construct with each other construct controlling for the other 8 constructs) into Table 
12 . The results from these correlational analyses will be detailed in a cross-study combined 2 analysis following the reporting of the results in Study 3. GASP Correlations

The major aim of this research was to test whether each level of motivation makes a For guilt NBE, only self-reliance $(p r=0.22, p=0.02)$ and social justice $(p r=0.21, p=$ unique contribution when all of the various scales are combined into a single analysis. Table 3 includes pair-wise correlations between each motivational construct and each moral emotion construct, but our main focus is the partial correlations between each of the motivational subscales with both the experiential and behavioral aspects of guilt and shame, looking for each subscale's effect over and above all of the other subscales' effects. 0.03 ) remained significantly correlated. Interestingly, this suggests that self-reliance and social justice each provides independent associations with the experience of guilt. This effect is consistent with the findings of Sheikh and Janoff-Bulman (2010), though this result indicates that the guilt can be associated both with failing to follow prescriptive rules for oneself and failing to follow those rules with respect to others. There were no significant effects of the promotion focus or the BAS scales independent of the MMS approach scales. For the behavioral guilt repair there were three significant independent associations. As with the experiential aspect of guilt above, there were associations with both self-reliance $(p r=0.25, p=0.01)$ and social justice $(p r=0.24, p=0.01)$. However, unlike guilt NBE, 
10.05 ). This suggests that although proneness to guilt feelings has an "approach"-based 2 foundation, the motivation to repair guilt is more complex with both "approach" and $3 \quad$ "avoidance" foundations.

For shame NSE, there was a positive association with social justice $(p r=0.21, p=$

$0.02)$ and the BIS subscale $(p r=0.34, p<0.001)$. Like guilt repair, this reflects

motivationally complex foundations for shame NSE. Shame, unlike guilt, is independently associated with behavioral inhibition, but it is also associated with the desire for positive end-states for others. That is, those who are more supportive of rules to do good for others are more likely to be prone to the experience of shame, perhaps due to the inherent public nature of such rules (see Janoff-Bulman \& Carnes, 2013).

For shame withdrawal, there was only a significant positive association with social order $(p r=0.32, p=0.001)$. These results suggest that the withdrawal associated with shame-inducing public infractions is more motivationally straightforward than the other moral emotions. It also confirms the "other" aspect of the social order subscale because these shame emotions are related to public rather than private ethical infractions. Discussion

What these results suggest is that when divided into experiential and behavioral aspects, motivations at multiple levels can contribute to a particular moral emotion or moral behavior independently and simultaneously. The BAS/BIS motivational construct makes distinct contributions to understanding moral emotions and their attendant behaviors independent of the MMS motivations and vice versa. Shame NSE, for example, appears to be independently and importantly associated with BIS motives. Although there was also some evidence of regulatory focus having associations with the behavior of guilt 
repair, these associations were no longer significant when they were tested combined with BAS/BIS and MMS.

In different ways, Studies 1 and 2 suggest that there are differences between MMS approach/avoidance motives, BIS/BAS, and regulatory focus motives. The purpose of Study 3 was to provide further and more comprehensive evidence for the distinct contributions of each of the three theories in relation to the Portrait Values Questionnaire (PVQ;

Schwartz et al, 2001). Would we find that the different motivational dimensions are associated with distinct value emphases?

The final study we conducted was designed to understand the different kinds of values associated with the different motivational levels. We turned to the PVQ to further differentiate the various scales from one another and paint a more detailed picture of how each relates to different values.

\section{Method}

\section{Participants}

One hundred sixty participants were recruited from Amazon's Mechanical Turk for the sum of $\$ 1.50$. Participants consisted of 76 males and 84 females. Age information was not collected, though approximately $85 \%(\mathrm{~N}=136)$ indicated having at least some college education. Since females (Ms $=5.91,3.39,3.02)$ rated themselves significantly higher on self-reliance $(t(158)=-2.52, p=0.01, d=-0.40)$, prevention $(t(158)=-2.42, p=0.02, d=-$ 23 0.38), and BIS $(t(158)=-2.92, p=0.004, d=-0.46)$ compared to males $(\mathrm{Ms}=5.45,3.06$, 2.73), we controlled for sex differences in each of the analyses below.

\section{Procedure}


The procedure was identical to the previous study, except that in place of the GASP, participants filled out the Portrait Values Questionnaire (PVQ; Schwartz et al, 2001). The PVQ contains 40 statements, each corresponding to one of 10 value subsets. The statements are designed so that participants may indicate the degree to which the person described in the statement is either like them or unlike them on a scale from 1 ("not like me") to 6 ("very much like me"). These scores are then combined in order to create scores direction, stimulation, hedonism, achievement, power, and security), which can then be combined into four larger value supersets (security, conformity, and tradition into conservation; benevolence and universalism into self-transcendence; self-direction and stimulation into openness; hedonism, achievement, and power into self-enhancement). To simplify the discussion of our findings, these latter four categories will be the main focus of the analyses below, though the associations between the three different motivational constructs and the 10 value subsets are available in Table 5 and illustrated in Figure 1. Analysis

We analyzed personal value endorsement using a crossed-random effects mixed regression model. We did this in order to factor out noise associated with individual differences and with value differences within our model. For example, each participant may endorse statements across values more or less strongly than other participants overall, and each value may be endorsed across participants more or less strongly than other values overall. Researchers have been explicitly called on to control for the former issue in the analysis of personal values in a related survey (Schwartz, 2009), but we believe the latter issue is important as well, since values can vary in their overall endorsement relative 
to one another considerably, particularly across cultures (Schwartz, 1994). This analytical approach allowed us to examine the relations between the various motivational scales and personal values while holding these factors constant.

We analyzed the effect of the various motivational constructs by interacting them with a dummy variable indicating whether the statement in question belongs to a particular subset or superset or not $(1=$ yes; $0=$ no $)$. This variable was then interacted with the motivational constructs predicting endorsement, while including random effects for individual participants and individual items in the model as noted above. The output from this model allows us to determine the degree to which particular motivational variables influence the degree to which certain categories of values receive higher or lower endorsement relative to other values. It is also worth noting that standardized beta coefficients can be misleading in mixed models, so we are instead reporting the significance tests and 95\% confidence intervals below.

Results

Before converting the data into a long format for our mixed model analysis, we first analyzed the partial correlations between the various motivational constructs in a manner identical to previous studies. These analyses are available in Table 4 , and will be examined in more detail in the combined analysis below. Following these analyses, we turned to the crossed-random effects model in order to assess the relations between the motivational variables and personal values.

As with the previous study, since our interest was primarily in the independent contribution of each construct, we only report the results of the combined analyses involving all of the scales here. However, we have included the basic relations between 
1 each of the motivational subscales and each of the 10 value subscales in Table 5 . We have 2 also included figures providing a visualization of these relations in Figure 2, in order to 3 illustrate their uniqueness.

Personal Values

In order to assess the independent contribution of each construct, it was necessary to examine the strength of the combined effects on each of these value categories. Including all of the constructs into a mixed model predicting self-enhancement, we found significant positive associations with BAS fun seeking $(z=3.64, p<0.001,95 \% \mathrm{CI}=[0.105,0.350])$ and BAS drive $(z=5.84, p<0.001,95 \% \mathrm{CI}=[0.292,0.587])$, and significant negative associations with self-restraint $(z=-3.37, p=0.001,95 \% \mathrm{CI}=[-0.267,-0.071])$. This set of relations appears to tell a general "approach" motivation story for self-enhancement, with positive associations for "approach" motives and negative associations for "avoidance" motives. But, there were two other associations that contradict such a simple "approach" story. There was a significant positive association with social order $(z=4.71, p<0.001$, $95 \% \mathrm{CI}=[0.075,0.183])$ and a significant negative association with social justice $(z=-5.99$, $p<0.001,95 \% \mathrm{CI}=[-0.238,-0.121])$. This shows a complex set of relations between selfenhancement values and both "approach" and "avoidance" motivational constructs, active at multiple motivational levels.

With respect to self-transcendence, there were independent effects across motivational constructs as well. There was a significant positive relation between selftranscendence and social justice $(z=10.88, p<0.001,95 \% \mathrm{CI}=[0.265,0.382])$, and significant negative associations between self-transcendence and social order $(z=-7.74, p$ $<0.001,95 \% \mathrm{CI}=[-0.264,-0.157])$ and prevention focus $(z=-2.61, p=0.01,95 \% \mathrm{CI}=[-$ 
$10.196,-0.028])$. This set of relations appears to tell a general approach motivation story for self-transcendence, with positive associations for "approach" motives and negative associations for "avoidance" motives. But, adding some additional complexity for a simple "approach" story was a significant negative association with BAS drive $(z=-6.29, p<0.001$, $95 \% \mathrm{CI}=[-0.615,-0.323])$. This reveals a less than simple set of relations to selftranscendence involving both "approach" and "avoidance" motives. Importantly, the relations cross motivational levels as well.

The relations between openness and conservation provided a different pattern of results. For openness, there were significant positive associations with the promotion focus $(z=2.26, p=0.02,95 \% \mathrm{CI}=[0.023,0.326])$ and BAS fun seeking $(z=6.33, p<0.001,95 \%$ $\mathrm{CI}=[0.311,0.590])$. There were also significant negative associations between openness and self-restraint $(z=-3.70, p<0.001,95 \% \mathrm{CI}=[-0.322,-0.099])$, social order $(z=-4.62, p<$ $0.001,95 \% \mathrm{CI}=[-0.205,-0.083])$, the prevention focus $(z=-2.78, p=0.006,95 \% \mathrm{CI}=[-$ $0.233,-0.040])$, and BIS $(z=-3.25, p=0.001,95 \% \mathrm{CI}=[-0.410,-0.102])$. Again, this set of relations appears to tell a comprehensive, multi-level motivational story for openness, with positive associations for "approach" motives and negative associations for "avoidance" motives. But, again, adding some additional complexity for purely an "approach" story was the significant negative association with BAS reward $(z=-1.97, p=0.048,95 \% \mathrm{CI}=[-0.430$, $-0.002])$.

Finally, with respect to conservation, there were significant positive associations with self-restraint $(z=7.03, p<0.001,95 \% \mathrm{CI}=[0.231,0.409])$, social order $(z=6.59, p<$ $0.001,95 \% \mathrm{CI}=[0.116,0.214])$, and the prevention focus $(z=3.14, p=0.002,95 \% \mathrm{CI}=$ $[0.046,0.201])$. There were significant negative associations between conservation and 
social justice $(z=-5.53, p<0.001,95 \% \mathrm{CI}=[-0.204,-0.097])$, the promotion focus $(z=-2.63$, $p=0.009,95 \% \mathrm{CI}=[-0.283,-0.041])$, and BAS fun seeking $(z=-9.27, p<0.001,95 \% \mathrm{CI}=[-$ $0.639,-0.416])$. This set of relations does tell a comprehensive avoidance story for conservation, crossing multiple levels of motivation, with positive associations for "avoidance" motives and negative associations with "approach" motives. The fact that there is a consistent "avoidance" story for conservation is worth noting because it does suggest that this value is closely associated with avoidance motives at different levels of motivational analysis (see Scholer \& Higgins, 2008). How this plays out exactly needs to be investigated more fully in future research.

These results confirm empirically that even when different motivational constructs have similar relations to certain values, they have independent associations for different underlying reasons consistent with their tapping into distinct motivational levels. Not only do each of these motivational constructs have different patterns of relationships to the various values (see Figure 2), many of these relations appear to be statistically independent of the relations with other motivational constructs, regardless of their connection to a theoretical "approach" or "avoidance" underlying construct. That is, for most of the value category cases, all three motivational levels have independent associations, and thus to understand the value fully requires taking all three distinct motivational constructs into account. Thus, some general approach-avoidance construct is insufficient. Combined Analysis of Scale Correlations

Before concluding, it is important to examine the relations among the three different scales across studies. Because some relations were not reliable across all three studies, it is best to discuss them through the use of a combined analysis. We combined the three 
samples into one dataset, and then ran partial correlations among the various constructs, controlling for sex (since there were significant sex differences in two of the three samples), sample source differences (two samples were drawn from Mechanical Turk and one from the Behavioral Research Lab at the Columbia Business School), and the other 8 constructs. The results are organized into Table 6.

If the approach/avoidance constructs measured by the MMS are indicative of regulatory focus and BIS/BAS, then there should at least be reliable correlations with the prescriptive constructs, promotion, and BAS scales on the one hand; and the proscriptive constructs, prevention, and the BIS scale on the other. Some associations were consistent with a general approach/avoidance construct hypothesis. For example, promotion focus and the BAS reward scales showed reliable positive associations with the approach-based self-reliance subscale of the moral motives (promotion focus: $p r=0.31, p<0.001$; BAS reward: $p r=0.20, p<0.001$ ). In addition, the avoidance-based social order scale was consistently negatively correlated with self-reliance $(p r=-0.25, p<0.001)$. However, the avoidance-based self-restraint scale was consistently the most strongly positively correlated with self-reliance $(p r=0.52, p<0.001)$. And, with the exception of a reliable negative association between self-restraint and BAS fun-seeking ( $p r=-0.13, p<0.01)$, there were no other relations between the MMS scales and either the regulatory focus or BIS/BAS scales that would be consistent with some overarching approach/avoidance motive. A few of the relations actually directly challenged this perspective, particularly with respect to social order. Social order, outside of the MMS, was most strongly and reliably positively associated with BAS drive $(p r=0.21, p<0.001)$, and it was not reliably 
associated with any other avoidance motives, except for the BIS with which it was reliably negatively associated $(p r=-0.13, p=0.001)$.

Controlling for the MMS approach/avoidance constructs in the partial correlations between the regulatory focus and BIS/BAS constructs revealed some additional effects. For $0.40, p<0.001)$ and positively associated with BAS Reward $(p r=0.16, p<0.001)$. We also found reliable negative associations between the prevention focus and both BAS fun seeking $(p r=-0.28, p<0.001)$ and BAS drive $(p r=-0.13, p<0.001)$. However, prevention focus was also reliably positively associated with BAS Reward ( $p r=0.13, p<0.001)$. Finally, the BAS subscales each had reliable correlations with one another, consistent with the past literature (Carver \& White, 1994).

Upon viewing these correlations, it is difficult to maintain the "one size fits all," single-level theory of motivation in which prescriptive and proscriptive morality, regulatory focus, and BAS/BIS are simply species of the approach/avoidance genus. It seems clear that the approach/avoidance moral motives, regulatory focus, and BIS/BAS all represent distinct constructs worthy of research and attention in their own right. Interestingly, if one assumes the independence of these various motivational constructs, some associations may be worthy of future empirical exploration. For example, why did BAS drive correlate positively with social order $(p r=0.21, p<0.001) ?$ In what way is behavioral drive in the service of social order? Perhaps behavioral activation as a selfregulatory approach tactic is especially useful for social restraint at the system level of avoidance. There were also relatively reliable (though small) negative correlations between the BIS on the one hand and social order on the other $(p r=-0.13, p=0.001)$. 
1 These correlations are quite modest in strength, but it may be interesting to explore in what ways an emphasis on social order involves a lower reactivity toward negative stimuli.

\section{General Discussion}

The purpose of our research was to establish the unique contributions of different

5 kinds of motivational constructs that are sometimes conflated together as simply approach/avoidance. Our findings suggest that treating the motivational constructs measured by MMS, the BIS/BAS scale, and the RFQ as essentially reflecting the same general approach/avoidance distinction would be unfortunate because they each have unique properties and unique associations with other psychological variables. Although

the establishment of approach/avoidance in the form of prescriptive versus proscriptive moral rules in the domain of morality has made a significant contribution, our findings suggest that its associations with at least two moral emotions and a wide range of personal values are distinct and independent from the associations with regulatory focus and BIS/BAS. Each of these three different motivational constructs makes unique, independent contributions to understanding moral emotions and personal values.

For example, past research has shown the relation between promotion focus and some openness values and prevention focus and some conservation values (Leikas, Lönnqvist, Verkasalo, \& Lindeman, 2009), but our research shows that one should not expect that the MMS motives or the BIS/BAS motives will necessarily behave in a similar way, and indeed our results showed that the relations were quite different. The relations that one approach/avoidance motivational distinction has with a moral phenomenon may not be the same as the relations another approach/avoidance motivational distinction has. 
Furthermore, even if two or more approach/avoidance motivational constructs have similar relations to other constructs in morality, our findings suggest that similar relations can exist independently for different reasons. For example, research has shown that the prevention focus is positively correlated with binding moral foundations (Cornwell \& Higgins, 2013), and theoretical models of approach/avoidance suggest that social order should also be correlated with these foundations (Janoff-Bulman \& Carnes, 2013). One might be tempted to assume that these two constructs are positively correlated with these foundations for the same reason (an emphasis on "avoidance"), but the present research suggests that this is not likely to be the case. In line with the results of Study 3 above, the prevention focus could be associated with the binding foundations due to its concerns with security and conformity (i.e., maintaining the status quo) rather than with stimulation and hedonism, whereas social order could be concerned with tradition and power rather than self-direction and universalism. Thus, for very different reasons, these distinct concerns of prevention and social order could be independently related to the binding foundations.

Before concluding, it is important to highlight some limitations of this research. First, though the sample size for Study 1 was substantial, the sample sizes for the subsequent two studies were merely adequate. Future research will need to ensure the reliability of these findings by making use of larger samples. Secondly, and most importantly, these studies only examined the effects of these constructs in cross-sectional assessments of moral attitudes. In order to most effectively assess the differences among the constructs that we outline here, future research will need to examine their differences via other means, such as experimental inductions, longitudinal analysis, and assessment of 
1 behavioral outcomes. The results in this paper show the significance of the distinctions among the constructs, but only future research can establish their importance.

In sum, it appears that the correlations among the various motivational constructs and their independent associations with moral emotions and personal values undermine the "one size fits all" single-level approach-avoidance theory of moral motivation. Instead, each of these motivational constructs has something unique to contribute to the field of moral psychology. This conclusion is consistent with a model of motivation that relies on distinct levels of analysis for approach-avoidance; one that distinguishes between approach-avoidance at the system level, the strategic level, and the tactical level (e.g., Scholer \& Higgins, 2008).

The incorporation of approach-avoidance motivation into the study of morality represents a significant theoretical step forward. But beyond this general approachavoidance perspective, the field would be well served by theoretically developing the separate impact on moral psychology of each the different approach-avoidance distinctions 18 19 


\section{References}

Camacho, C. J., Higgins, E. T., \& Luger, L. (2003). Moral value transfer from regulatory fit: What feels right is right and what feels wrong is wrong. Journal of Personality and Social Psychology, 84(3), 498-510.

Carver, C. S., \& Scheier, M. F. (2001). On the Self-Regulation of Behavior. Cambridge, UK: Cambridge University Press. affective responses to impending reward and punishment: the BIS/BAS scales. Journal of Personality and Social Psychology, 67(2), 319-333.

Cohen, T. R., Wolf, S. T., Panter, A. T., \& Insko, C. A. (2011). Introducing the GASP scale: a new measure of guilt and shame proneness. Journal of Personality and Social Psychology, 100(5), 947-966.

Carver, C. S., \& White, T. L. (1994). Behavioral inhibition, behavioral activation, and

Cornwell, J. F. M. \& Higgins, E. T. (2013). Morality and its relation to political ideology: The role of promotion and prevention concerns. Personality and Social Psychology Bulletin, 39(9), 1164-1172.

Elliot, A. J. (1999). Approach and avoidance motivation and achievement goals. Educational Psychologist, 34(3), 169-189.

Förster, J., Higgins, E. T., \& Idson, L. C. (1998). Approach and avoidance strength during goal attainment: Regulatory focus and the "goal looms larger" effect. Journal of Personality and Social Psychology, 75, 1115-1131.

Freitas, A. L., Liberman, N., \& Higgins, E. T. (2002). Regulatory fit and resisting temptation during goal pursuit. Journal of Experimental Social Psychology, 38(3), 291-298. 
Greene, J. \& Haidt, J. (2002). How (and where) does moral judgment work? Trends in Cognitive Sciences, 6(12), 517-523.

Hair, J.F., Tatham, R.L., Anderson, R.E., \& Black, W. (1998). Multivariate Data Analysis (5th Edition). Prentice Hall: London, UK.

Hamlin, J. K., Wynn, K., \& Bloom, P. (2007). Social evaluation by preverbal infants. Nature, 450(7169), 557-559.

Higgins, E. T. (1987). Self-discrepancy: A theory relating self and affect. Psychological Review, 94, 319-340.

Higgins, E. T. (1997). Beyond pleasure and pain. American psychologist, 52(12), 1280-1300.

Higgins, E. T. (1998). Promotion and prevention: Regulatory focus as a motivational principle. Advances in Experimental Social Psychology, 30, 1-46.

Higgins, E. T., Friedman, R. S., Harlow, R. E., Idson, L. C., Ayduk, O. N., Taylor, A. (2001). Achievement orientations from subjective histories of success: Promotion pride versus prevention pride. European Journal of Social Psychology, 31, 3-23.

Janoff-Bulman, R. \& Carnes, N. (2013). Surveying the moral landscape: Moral motives and group-based moralities. Personality and Social Psychology Review, 17(3), 219-236.

Janoff-Bulman, R., Sheikh, S., \& Baldacci, K. G. (2008). Mapping moral motives: Approach, avoidance, and political orientation. Journal of Experimental Social Psychology, 44(4), 1091-1099.

Janoff-Bulman, R., Sheikh, S., \& Hepp, S. (2009). Proscriptive versus prescriptive morality: Two faces of moral regulation. Journal of Personality and Social Psychology, 96(3), 521-537. 
Kruglanski, A. W., Thompson, E. P., Higgins, E. T., Atash, M., Pierro, A., Shah, J. Y., \& Spiegel, S. (2000). To" do the right thing" or to" just do it": locomotion and assessment as distinct self-regulatory imperatives. Journal of Personality and Social Psychology, $79(5), 793-815$.

Leikas, S., Lönnqvist, J. E., Verkasalo, M., \& Lindeman, M. (2009). Regulatory focus systems and personal values. European Journal of Social Psychology, 39(3), 415-429.

Lockwood, P., Jordan, C. H., \& Kunda, Z. (2002). Motivation by positive or negative role models: Regulatory focus determines who will best inspire us. Journal of Personality and Social Psychology, 83(4), 854-864.

Olatunji, B. O., Haidt, J., McKay, D., \& David, B. (2008). Core, animal reminder, and contamination disgust: Three kinds of disgust with distinct personality, behavioral, physiological, and clinical correlates. Journal of Research in Personality, 42(5), 12431259.

1 Scholer, A. A., \& Higgins, E. T. (2008). Distinguishing levels of approach and avoidance: An analysis using regulatory focus theory. In Elliot, A. J. (Ed.), Handbook of Approach and Avoidance Motivation (pp. 489-503). New York, NY: Psychology Press.

Scholer, A. A., Zou, X., Fujita, K., Stroessner, S. J., \& Higgins, E. T. (2010). When risk seeking becomes a motivational necessity. Journal of Personality and Social Psychology, 99(2), $215-231$.

Schwartz, S. H. (1994). Are there universal aspects in the structure and contents of human values?. Journal of Social Issues, 50(4), 19-45. values, and voting: A longitudinal analysis. Political Psychology, 31(3), 421-452. 
Schwartz, S. H., \& Howard, J. A. (1984). Internalized values as motivators of altruism. In Development and Maintenance of Prosocial Behavior (pp. 229-255). New York, NY: Plenum Press.

Schwartz, S. H. (2009). Draft Users Manual: Proper Use of the Schwarz Value Survey, version 14 January 2009, compiled by Romie F. Littrell. Auckland, New Zealand: Centre for Cross Cultural Comparisons, http://www.crossculturalcentre.homestead.com.

Schwartz, S. H., Melech, G., Lehmann, A., Burgess, S., Harris, M., \& Owens, V. (2001). Extending the cross-cultural validity of the theory of basic human values with a different method of measurement. Journal of Cross-Cultural Psychology, 32(5), 519542.

Shah, J. (2003). The motivational looking glass: How significant others implicitly affect goal appraisals. Journal of Personality and Social Psychology, 85, 424-439.

Sheikh, S., \& Janoff-Bulman, R. (2010). The "shoulds" and "should nots" of moral emotions: A self-regulatory perspective on shame and guilt. Personality and Social Psychology Bulletin, 36(2), 213-224.

Strauman, T. J., Detloff, A. M., Sestokas, R., Smith, D. V., Goetz, E. L., Rivera, C., \& Kwapil, L. (2013). What shall I be, what must I be: neural correlates of personal goal activation. Frontiers in Integrative Neuroscience, 6.

Strauman, T. J., \& Wilson, W. A. (2010). Behavioral activation/inhibition and regulatory focus as distinct levels of analysis. In Hoyle, R. H. (Ed.), Handbook of Personality and Self-Regulation (pp. 447-473). Malden, MA: Blackwell. 
Summerville, A., \& Roese, N. J. (2008). Self-report measures of individual differences in regulatory focus: A cautionary note. Journal of Research in Personality, 42(1), 247254.

Tangney, J. P., Dearing, R. L., Wagner, P. E., \& Gramzow, R. H. (2000). The Test of SelfConscious Affect - 3 (TOSCA-3). George Mason University, Fairfax, VA.

Van den Bos, K., Müller, P. A., \& Damen, T. (2011). A behavioral disinhibition hypothesis of interventions in moral dilemmas. Emotion Review, 3(3), 281-283.

Wisneski, D. C. (2014). Exploring differences in liberal and conservative moral conviction and moral motivation. Chicago, IL: (PhD), University of Illinois at Chicago.

Zou, X., Scholer, A. A., Higgins, E. T. (2014). In pursuit of progress: Promotion motivation and risk preference in the domain of gains. Journal of Personality and Social Psychology, 106, 183-201. 
1 Table 1: Partial correlations (controlling for sex differences and the other constructs)

2 between the various motivational constructs in Study 1.

\begin{tabular}{|c|c|c|c|c|c|c|c|c|c|}
\hline Scale & $\begin{array}{c}\text { Self- } \\
\text { Reliance }\end{array}$ & $\begin{array}{c}\text { Self- } \\
\text { Restraint }\end{array}$ & $\begin{array}{c}\text { Social } \\
\text { Justice }\end{array}$ & $\begin{array}{l}\text { Social } \\
\text { Order }\end{array}$ & Promotion & Prevention & BAS FS & BAS R & BAS D \\
\hline $\begin{array}{c}\text { Self- } \\
\text { Restraint }\end{array}$ & $0.53^{* * *}$ & --- & --- & --- & --- & --- & --- & --- & --- \\
\hline $\begin{array}{c}\text { Social } \\
\text { Justice }\end{array}$ & 0.04 & 0.08 & --- & --- & --- & --- & --- & --- & --- \\
\hline $\begin{array}{l}\text { Social } \\
\text { Order }\end{array}$ & $-0.21^{* * *}$ & $0.22^{* * *}$ & $0.12^{*}$ & --- & --- & --- & --- & --- & --- \\
\hline Promotion & $0.29^{* * *}$ & -0.00 & 0.02 & $-0.17^{* * *}$ & --- & --- & --- & --- & --- \\
\hline Prevention & 0.07 & 0.01 & -0.07 & $0.10^{*}$ & $0.15^{* *}$ & --- & --- & --- & -- \\
\hline $\begin{array}{l}\text { BAS Fun } \\
\text { Seeking }\end{array}$ & $-0.11^{*}$ & $-0.09 \dagger$ & -0.00 & -0.03 & 0.01 & $-0.33^{* * *}$ & --- & --- & --- \\
\hline $\begin{array}{c}\text { BAS } \\
\text { Reward }\end{array}$ & $0.22^{* * *}$ & $0.13^{*}$ & $0.14^{* *}$ & $-0.13^{*}$ & $0.10^{*}$ & $0.17^{* * *}$ & $0.31^{* * *}$ & --- & --- \\
\hline BAS Drive & 0.07 & 0.03 & $-0.12^{*}$ & $0.26^{* * *}$ & $0.17^{* * *}$ & $-0.19^{* * *}$ & $0.27^{* * *}$ & $0.35^{* * *}$ & --- \\
\hline BIS & -0.05 & 0.03 & 0.01 & $-0.12^{*}$ & $-0.44^{* * *}$ & -0.02 & $-0.14^{* *}$ & $0.36^{* * *}$ & -0.08 \\
\hline
\end{tabular}


Table 2: Partial correlations between the various motivational constructs (controlling for

2 effects of associations with other constructs) in Study 2.

\begin{tabular}{|c|c|c|c|c|c|c|c|c|c|}
\hline Scale & $\begin{array}{c}\text { Self- } \\
\text { Reliance }\end{array}$ & $\begin{array}{c}\text { Self- } \\
\text { Restraint }\end{array}$ & $\begin{array}{c}\text { Social } \\
\text { Justice }\end{array}$ & $\begin{array}{l}\text { Social } \\
\text { Order }\end{array}$ & Promotion & Prevention & BAS FS & BAS R & BAS D \\
\hline $\begin{array}{c}\text { Self- } \\
\text { Restraint }\end{array}$ & $0.46^{* * *}$ & --- & --- & --- & --- & --- & --- & --- & --- \\
\hline $\begin{array}{l}\text { Social } \\
\text { Justice }\end{array}$ & 0.04 & $0.20^{*}$ & --- & --- & --- & --- & --- & --- & --- \\
\hline $\begin{array}{l}\text { Social } \\
\text { Order }\end{array}$ & $-0.25^{* *}$ & $0.29^{* *}$ & -0.08 & --- & --- & --- & --- & --- & --- \\
\hline Promotion & $0.40^{* * *}$ & $-0.22^{*}$ & $0.18 \dagger$ & -0.01 & --- & --- & --- & --- & --- \\
\hline Prevention & -0.07 & 0.15 & -0.12 & $-0.19 *$ & $0.19 *$ & --- & --- & --- & --- \\
\hline $\begin{array}{l}\text { BAS Fun } \\
\text { Seeking }\end{array}$ & -0.02 & $-0.25^{* *}$ & $0.35^{* * *}$ & 0.00 & $-0.23^{*}$ & 0.03 & --- & --- & --- \\
\hline $\begin{array}{c}\text { BAS } \\
\text { Reward }\end{array}$ & 0.15 & 0.05 & $-0.17 \dagger$ & -0.15 & $0.18 \dagger$ & 0.12 & $0.36^{* * *}$ & --- & --- \\
\hline BAS Drive & 0.12 & 0.08 & -0.12 & $0.18 \dagger$ & 0.10 & $-0.19 *$ & $0.27^{* *}$ & $0.37^{* * *}$ & --- \\
\hline BIS & 0.02 & 0.14 & 0.09 & 0.04 & -0.14 & -0.01 & 0.01 & $0.44^{* * *}$ & $-0.33^{* * *}$ \\
\hline
\end{tabular}


Table 3: Pair-wise correlations and partial correlations between the various constructs and the four elements of guilt and shame.

\begin{tabular}{|c|c|c|c|c|}
\hline Scale & Guilt NBE & Shame NSE & Guilt Repair & $\begin{array}{c}\text { Shame } \\
\text { Withdraw }\end{array}$ \\
\hline \multicolumn{5}{|c|}{ Pair-Wise Correlations } \\
\hline Self-Reliance & $0.33^{* * *}$ & $0.27^{* *}$ & $0.49 * * *$ & 0.06 \\
\hline Self-Restraint & $0.29 * *$ & $0.28^{* *}$ & $0.40^{* * *}$ & $0.17 \dagger$ \\
\hline Social Justice & $0.24^{* *}$ & $0.25^{* *}$ & $0.30^{* *}$ & 0.10 \\
\hline Social Order & 0.00 & -0.11 & $-0.16 \dagger$ & $0.33^{* * *}$ \\
\hline Promotion & 0.09 & -0.02 & $0.29 * *$ & -0.10 \\
\hline Prevention & 0.05 & 0.14 & $0.24^{* *}$ & $-0.16 \dagger$ \\
\hline $\begin{array}{l}\text { BAS Fun } \\
\text { Seeking }\end{array}$ & -0.02 & 0.03 & 0.04 & -0.06 \\
\hline BAS Reward & $0.16 \dagger$ & $0.23^{*}$ & $0.34^{* * *}$ & 0.08 \\
\hline BAS Drive & 0.01 & -0.14 & 0.02 & 0.04 \\
\hline BIS & $0.23^{*}$ & $0.49 * * *$ & $0.35^{* * *}$ & $0.18^{*}$ \\
\hline \multicolumn{5}{|c|}{ Partial Correlations } \\
\hline Self-Reliance & $0.22^{*}$ & $0.18 \dagger$ & $0.25^{* *}$ & 0.08 \\
\hline Self-Restraint & 0.06 & 0.07 & $0.18 \dagger$ & -0.02 \\
\hline Social Justice & $0.21^{*}$ & $0.21^{*}$ & $0.24^{*}$ & 0.15 \\
\hline Social Order & 0.08 & -0.03 & -0.02 & $0.32^{* *}$ \\
\hline Promotion & -0.07 & $-0.16 \dagger$ & 0.07 & -0.12 \\
\hline Prevention & 0.02 & 0.08 & $0.17 \dagger$ & -0.11 \\
\hline $\begin{array}{l}\text { BAS Fun } \\
\text { Seeking }\end{array}$ & -0.10 & -0.07 & -0.07 & $-0.17 \dagger$ \\
\hline BAS Reward & 0.06 & 0.11 & 0.14 & 0.15 \\
\hline BAS Drive & -0.04 & -0.14 & -0.10 & -0.00 \\
\hline BIS & 0.11 & $0.34^{* * *}$ & $0.19^{*}$ & 0.12 \\
\hline
\end{tabular}


Table 4: Partial correlations (controlling for sex differences and relations with other constructs) between the various motivational constructs in Study 3.

\begin{tabular}{|c|c|c|c|c|c|c|c|c|c|}
\hline Scale & $\begin{array}{c}\text { Self- } \\
\text { Reliance }\end{array}$ & $\begin{array}{c}\text { Self- } \\
\text { Restraint }\end{array}$ & $\begin{array}{c}\text { Social } \\
\text { Justice }\end{array}$ & $\begin{array}{l}\text { Social } \\
\text { Order }\end{array}$ & Promotion & Prevention & BAS FS & BAS R & BAS D \\
\hline $\begin{array}{c}\text { Self- } \\
\text { Restraint }\end{array}$ & $0.55^{* * *}$ & --- & --- & -- & --- & --- & --- & --- & -- \\
\hline $\begin{array}{c}\text { Social } \\
\text { Justice }\end{array}$ & $0.23^{* *}$ & -0.02 & --- & --- & --- & --- & --- & --- & --- \\
\hline $\begin{array}{l}\text { Social } \\
\text { Order }\end{array}$ & $-0.36^{* * *}$ & $0.40^{* * *}$ & 0.07 & --- & --- & --- & --- & --- & --- \\
\hline Promotion & $0.26^{* *}$ & 0.02 & -0.05 & -0.07 & --- & --- & --- & -- & --- \\
\hline Prevention & -0.06 & -0.04 & 0.09 & $-0.15 \dagger$ & $0.17^{*}$ & --- & --- & --- & --- \\
\hline $\begin{array}{l}\text { BAS Fun } \\
\text { Seeking }\end{array}$ & 0.01 & -0.06 & 0.12 & -0.09 & -0.10 & $-0.34^{* * *}$ & --- & --- & --- \\
\hline $\begin{array}{c}\text { BAS } \\
\text { Reward }\end{array}$ & $0.17^{*}$ & $0.14 \dagger$ & 0.02 & -0.00 & $0.27^{* * *}$ & 0.06 & $0.18^{*}$ & --- & --- \\
\hline BAS Drive & -0.05 & 0.02 & -0.02 & $0.18^{*}$ & 0.11 & -0.01 & $0.35^{* * *}$ & $0.30^{* * *}$ & --- \\
\hline BIS & -0.08 & $0.20^{*}$ & $0.14 \dagger$ & $-0.21^{* *}$ & $-0.48^{* * *}$ & 0.04 & $-0.17^{*}$ & $0.37^{* * *}$ & $-0.14 \dagger$ \\
\hline
\end{tabular}


Table 5: Unstandardized beta coefficients (and standard errors in parentheses) of each motivational construct predicting each subset of personal values.

\begin{tabular}{lcccc}
\hline \multicolumn{1}{c}{ Value } & Self-Reliance & Self-Restraint & Social Justice & Social Order \\
\hline Conformity & $-0.06(0.05)$ & $0.27(0.05)^{* * *}$ & $-0.12(0.04)^{* *}$ & $0.17(0.03)^{* * *}$ \\
Tradition & $-0.10(0.05) \dagger$ & $0.18(0.05)^{* * *}$ & $-0.14(0.04)^{* *}$ & $0.23(0.03)^{* * *}$ \\
Benevolence & $0.08(0.05)$ & $0.05(0.05)$ & $0.20(0.04)^{* * *}$ & $-0.14(0.03)^{* * *}$ \\
Universalism & $0.11(0.04)^{*}$ & $-0.14(0.04)^{* *}$ & $0.31(0.03)^{* * *}$ & $-0.26(0.03)^{* * *}$ \\
Self-Direction & $0.20(0.05)^{* * *}$ & $-0.11(0.05)^{*}$ & $0.07(0.04) \dagger$ & $-0.22(0.03)^{* * *}$ \\
Stimulation & $-0.13(0.06)^{*}$ & $-0.26(0.06)^{* * *}$ & $-0.03(0.05)$ & $0.03(0.04)$ \\
Hedonism & $-0.09(0.06)$ & $-0.19(0.06)^{* *}$ & $-0.02(0.05)$ & $0.02(0.04)$ \\
Achievement & $-0.01(0.05)$ & $0.02(0.05)$ & $-0.10(0.04)^{*}$ & $0.09(0.03)^{* *}$ \\
Power & $-0.39(0.06)^{* * *}$ & $-0.20(0.06)^{* *}$ & $-0.34(0.05)^{* * *}$ & $0.25(0.09)^{* * *}$ \\
Security & $0.16(0.05)^{* *}$ & $0.23(0.05)^{* * *}$ & $-0.04(0.04)$ & $-0.00(0.03)$
\end{tabular}

\begin{tabular}{lcc}
\hline & Promotion & Prevention \\
\hline Conformity & $-0.14(0.07) \dagger$ & $0.27(0.06)^{* * *}$ \\
Tradition & $-0.08(0.07)$ & $0.06(0.06)$ \\
Benevolence & $0.08(0.07)$ & $0.03(0.06)$ \\
Universalism & $-0.06(0.06)$ & $0.01(0.05)$ \\
Self-Direction & $0.25(0.07)^{* *}$ & $-0.03(0.06)$ \\
Stimulation & $0.20(0.08)^{*}$ & $-0.41(0.06)^{* * *}$ \\
Hedonism & $-0.19(0.08)^{*}$ & $-0.18(0.06)^{* *}$ \\
Achievement & $0.12(0.07) \dagger$ & $0.06(0.06)$ \\
Power & $-0.07(0.08)$ & $-0.13(0.06)^{*}$ \\
Security & $-0.09(0.07)$ & $0.12(0.05)^{*}$ \\
\hline \multicolumn{2}{c}{ Bas Reward } & BAS Drive \\
\hline
\end{tabular}




\begin{tabular}{|c|c|c|c|c|}
\hline Tradition & $-0.46(0.07)^{* * *}$ & $-0.21(0.10)^{*}$ & $-0.28(0.09)^{* *}$ & $0.05(0.08)$ \\
\hline Benevolence & $-0.01(0.07)$ & $0.03(0.10)$ & $-0.36(0.09)^{* * *}$ & $0.14(0.08) \dagger$ \\
\hline Universalism & $-0.05(0.06)$ & $-0.02(0.09)$ & $-0.43(0.07)^{* * *}$ & $0.16(0.07)^{*}$ \\
\hline Self-Direction & $0.10(0.07)$ & $0.05(0.10)$ & $0.08(0.09)$ & $-0.19(0.08)^{*}$ \\
\hline Stimulation & $1.04(0.08)^{* * *}$ & $-0.17(0.12)$ & $0.55(0.10)^{* * *}$ & $-0.72(0.09)^{* * *}$ \\
\hline Hedonism & $0.58(0.08)^{* * *}$ & $-0.08(0.12)$ & $0.24(0.10)^{*}$ & $-0.15(0.09) \dagger$ \\
\hline Achievement & $0.16(0.07)^{*}$ & $0.42(0.10)^{* * *}$ & $0.52(0.09)^{* * *}$ & $0.07(0.08)$ \\
\hline Power & $0.06(0.08)$ & $-0.42(0.12)^{* * *}$ & $0.48(0.10)^{* * *}$ & $-0.42(0.09)^{* * *}$ \\
\hline Security & $-0.44(0.07)^{* * *}$ & $0.15(0.09)$ & $0.00(0.08)$ & $0.36(0.07)^{* * *}$ \\
\hline
\end{tabular}


1 Table 6: Partial correlations (controlling for sex difference, sample differences, and other

2 constructs) among the various motivational constructs in the combined analysis sample.

3 Bolded associations were consistently at least marginally significant across all three studies.

$4 \quad$ Italicized associations were consistently at least marginally significant across two studies.

5 All of the remaining associations were significant in only one study and the combined

6 analysis or only in the combined analysis.

\begin{tabular}{|c|c|c|c|c|c|c|c|c|c|}
\hline Scale & $\begin{array}{c}\text { Self- } \\
\text { Reliance }\end{array}$ & $\begin{array}{c}\text { Self- } \\
\text { Restraint }\end{array}$ & $\begin{array}{c}\text { Social } \\
\text { Justice }\end{array}$ & $\begin{array}{l}\text { Social } \\
\text { Order }\end{array}$ & Promotion & Prevention & BAS FS & BAS R & BAS D \\
\hline $\begin{array}{c}\text { Self- } \\
\text { Restraint }\end{array}$ & $0.52^{* * *}$ & --- & --- & --- & --- & --- & --- & --- & --- \\
\hline $\begin{array}{c}\text { Social } \\
\text { Justice }\end{array}$ & $0.09 *$ & 0.07 & --- & --- & --- & --- & -- & --- & --- \\
\hline $\begin{array}{l}\text { Social } \\
\text { Order }\end{array}$ & $-0.25^{* * *}$ & $0.28^{* * *}$ & $0.07 \dagger$ & --- & --- & --- & --- & --- & --- \\
\hline Promotion & $0.31^{* * *}$ & -0.04 & 0.01 & $-0.11^{* *}$ & --- & --- & --- & --- & --- \\
\hline Prevention & 0.03 & -0.01 & -0.02 & -0.01 & $0.15^{* * *}$ & --- & --- & --- & --- \\
\hline $\begin{array}{l}\text { BAS Fun } \\
\text { Seeking }\end{array}$ & -0.06 & $-0.13^{* *}$ & $0.08^{*}$ & -0.06 & -0.04 & $-0.28^{* * *}$ & --- & --- & --- \\
\hline $\begin{array}{c}\text { BAS } \\
\text { Reward }\end{array}$ & $0.20^{* * *}$ & $0.12^{* *}$ & $0.07 \dagger$ & $-0.08^{*}$ & $0.16^{* * *}$ & $0.13^{* * *}$ & $0.28^{* * *}$ & --- & --- \\
\hline BAS Drive & 0.06 & -0.02 & $-0.10^{*}$ & $0.21^{* * *}$ & $0.13^{* * *}$ & $-0.13^{* * *}$ & $0.31^{* * *}$ & $0.33^{* * *}$ & --- \\
\hline BIS & -0.03 & 0.05 & 0.06 & $-0.13^{* *}$ & $-0.40^{* * *}$ & 0.02 & $-0.10^{* *}$ & $0.38^{* * *}$ & $-0.13^{* *}$ \\
\hline
\end{tabular}


Figure 1: An example of how all three motivational levels can be simultaneously active in taking moral action.

\section{System-Level \\ Tactical-Level}
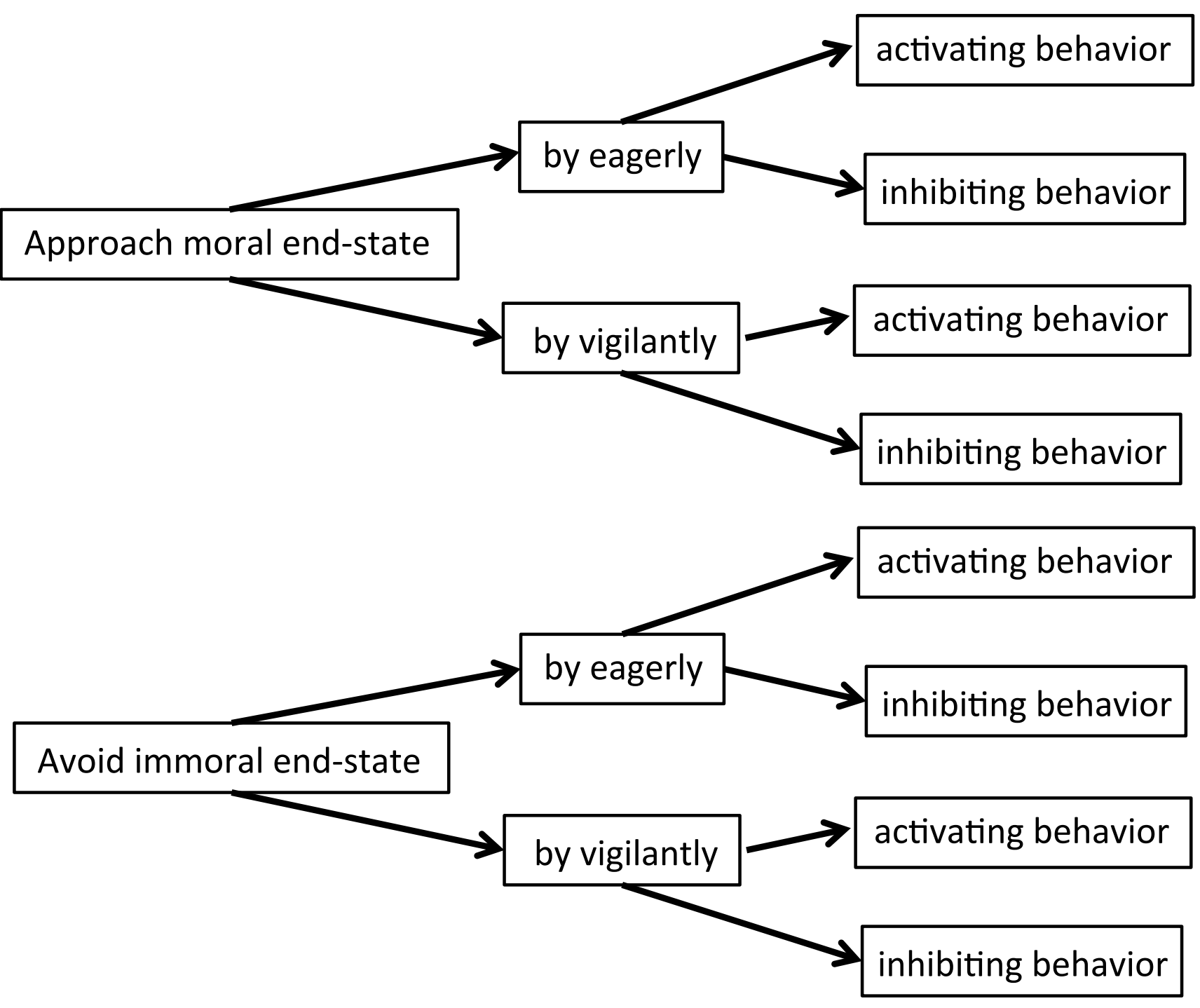
Figure 2: Visualizations of the various constructs' relations to the 10 value subsets. The visualization was accomplished by taking the mean level of endorsement across participants and adding it again multiplied by the beta coefficient from Table 6 . Greater distance from the center indicates a greater level of endorsement.
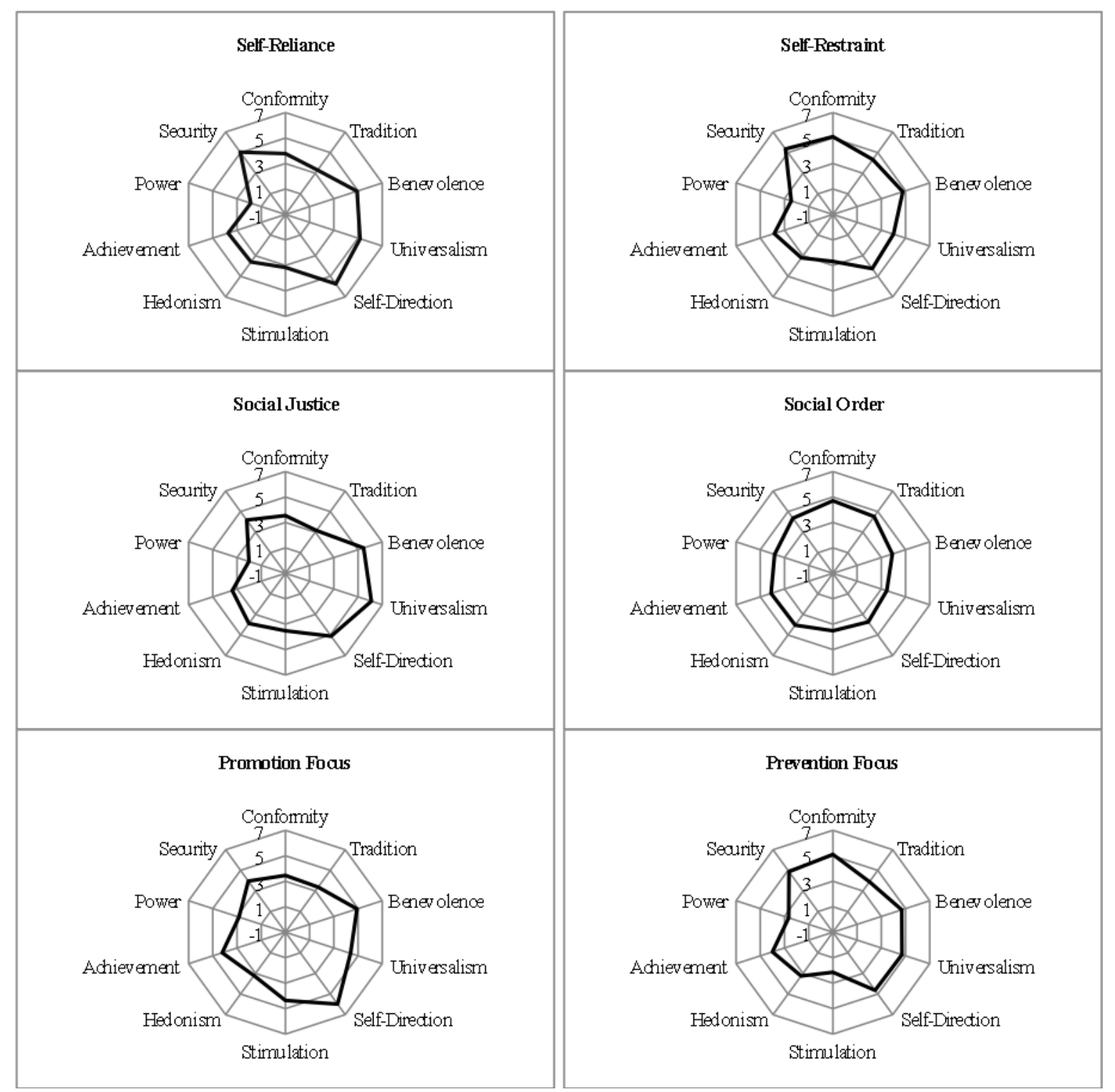


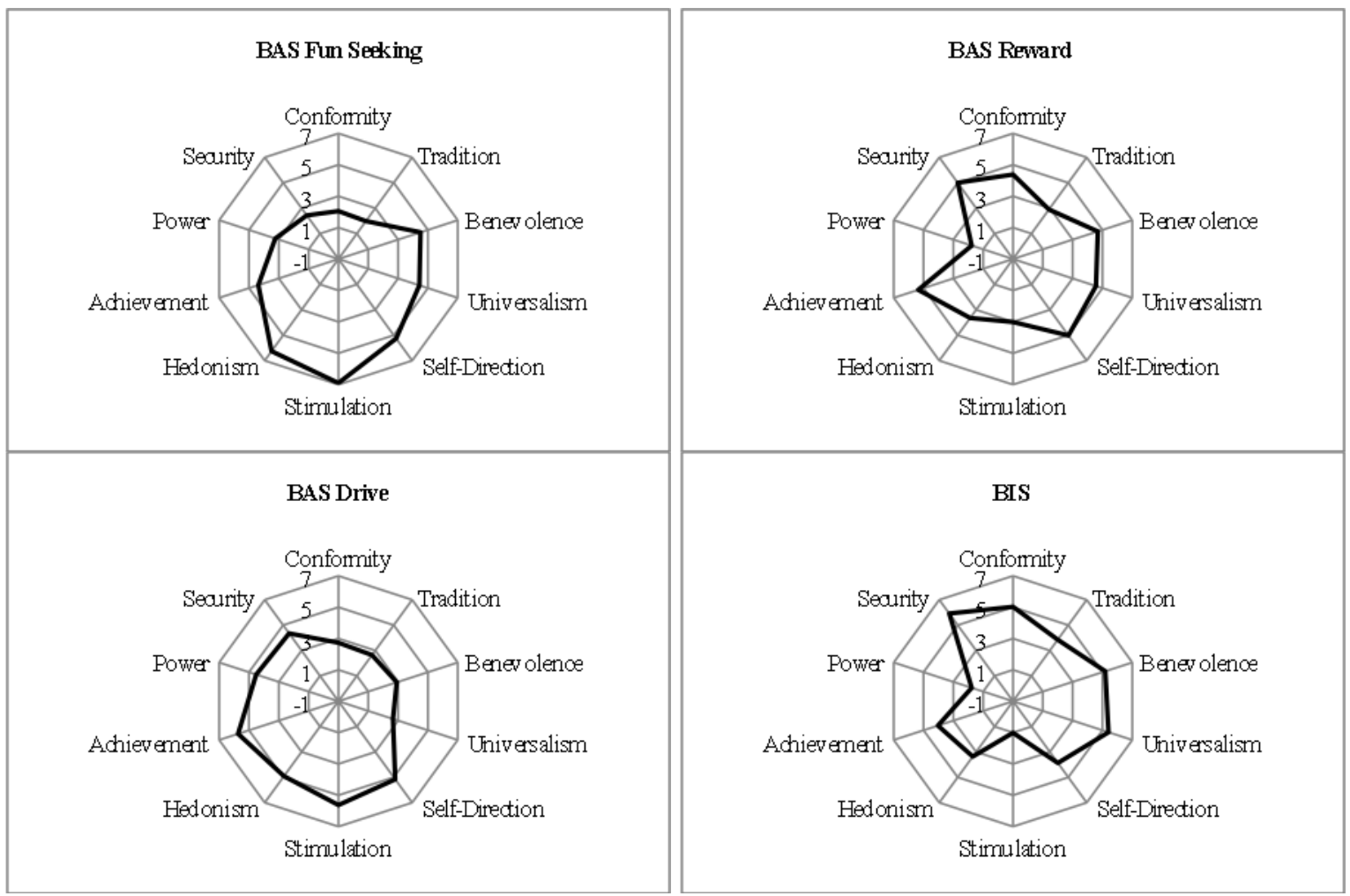

